\title{
Psychological time as a predictor of economic mind: Evidence from Russia and Japan
}

\author{
Ekaterina Zabelina ${ }^{1, *}$, Olga Deyneka $^{2}$, and Elvina Yagnakova ${ }^{3}$ \\ ${ }^{1}$ Chelyabinsk State University, Chelyabinsk, Russia \\ ${ }^{2}$ Saint Petersburg State University, Saint Petersburg, Russia \\ ${ }^{3}$ Public Chamber of Chelyabinsk region, Chelyabinsk, Russia
}

\begin{abstract}
Today, in the conditions of virtual space, a huge flow of information, accelerating subjective time are taking place in everyday life including the economic sphere. Economic mind in the context of globalization reflects the phenomena and relationships in the economic sphere that exist not only in the real market, but also in the virtual world of goods and services. In this regard, the scientific interest is the question of how ideas about time change in the global society, and what role they play in the shaping of the economic mind of an individual. The purpose of the study is to determine what characteristics of psychological time predict the features of the economic mind of young people in Russia and Japan. In the study $(\mathrm{N}=540)$, a more systematic determination of the economic mind of the Japanese was revealed, including not only orientation toward the future, but also taking into account past experience, as well as feelings in the present. In the formation of economic attitudes, Russian students are more oriented toward their future. The affective component of psychological time makes a greater contribution to the shaping of economic attitudes (the value of independent economic achievements, activity in the banking sector, etc.) of the Russian students, and the cognitive component - for Japanese students. This fact indicates a less serious relation to economic realities of the students in Russia compared to the Japanese.
\end{abstract}

\section{Introduction}

In the current conditions of growing dynamics of events in the virtual space and a huge flow of information that breaks into the daily life, there have been some changes in human consciousness, including the economic mind (Zabelina, Deyneka and Tsiring, 2019). Economic mind in the context of globalization is a reflection of phenomena and objects in the area of economic relations that exist not only in the real market but also in the virtual world of goods and services. In this regard, it is of scientific interest to explore how perception of time change in the present circumstances, and what role does it play in shaping the economic mind of an individual.

\footnotetext{
* Corresponding author: katya_k@mail.ru
} 
Although there are different perspectives on the structure of economic mind in science, most scholars acknowledge that its essential elements are economic relations and attitudes (Deyneka, 2011; Zabelina, Deyneka and Tsiring, 2019). The concept of attitude has been widely used in social psychology since the first third of the 20th century. In a broader sense, attitude is defined as "a relatively enduring organization of beliefs around an object or situation predisposing one to respond in some preferential manner" (Rokeach, 1986, p. 112). Conventionally, there are three components in the structure of attitudes - cognitive, affective, and behavioral factors (Smith, 1986) - which are closely related (Dinauer and Fink, 2005; Harding et al., 1954; Huskinson and Haddock, 2006; Krech and Crutchfield, 1948; Rosenberg, 1960), though they even may contradict one another (Armitage and Conner, 2000; Chaiken and Yates, 1985; Conner and Sparks, 2002).

The economic attitudes of individuals and social groups were most actively studied in the last quarter of the 20th century. In particular, research focused on attitudes toward unemployment (Kalil et al., 2001; Lewis and Furnham, 1986; Furnham, 1982), attitudes toward saving (Furnham, 1985), attitudes in debt and consumer behavior (Lea et al., 1993; Lea et al., 1995; Mewse et al., 2010), money attitudes (Furnham, 1996; Von Stumm et al., 2013), and investment attitudes (Antonides and Van Der Sar, 1990). In the framework of this particular study, it is worth examining the study on the attitude toward work in conjunction with the attitude toward money and motivation on the sample of students from Britain and Japan (Lynn et al., 1993). The authors suggest a mutual relationship among the interconnection of economic growth in the country, the competitiveness of motivation, and strong money beliefs based on a sample of Japanese students.

The economic mind of young people, which includes economic attitudes, reflects the relationship with the culture that dominates in society. In the first place, cultural factors actively influence economic mind and behavior as their integral element. Secondly, social and cultural factors are the variable that can vary from one community to another, from one historical period to another. In the end, what is defined (here and now) as desirable or rational has a specific historical-cultural content (Harikawa and Atsushi, 2007). Secondly, social and cultural factors are a variable that can vary from one community to another, from one historical period to another. In the end, what is defined (here and now) as desirable or rational has a specific historical-cultural content (Harikawa and Atsushi, 2007).

From this perspective, mind and behavior appear as the source, bearer, and product of culture. In one's behavior, culture develops at least three aspects: cognitive - acquired knowledge and skills; value - acquired standards of behavior; symbolic - developed ways to identify and interpret reality. Culture performs two main types of functions. The first is the regulatory function, performed by means of ready-to-use conceptual schemes and accumulated databases, universally accepted conventions and norms, and sets of wellestablished rituals and symbols to which any action, as well as economic activity, must relate. The second is the constitutive functions that are implemented through cognitive practices and ways of conveying the information, role-playing, and the redefinition of situations in the process of economic action (Horikawa Atsushi, 2007).

Psychological time, which is defined as a psychologically mediated reflection of objective time (duration and sequence of events, immersion in the past, present or future, ability to correlate one's behavior with the rhythms of social life, the perception of the value of time, etc.), is also largely determined by culture, primarily through language (Graham, 1981: Levine, 1997; Vale, Flynn and Kendal, 2012; Trompenaars and Hampden-Turner, 1997).

This study is to identify temporary predictors of the economic mind of young people in Russia and Japan. Japan is very much distinct from other European and Asian countries in many aspects. The Japanese are committed to preserving their national traditions intact, so it would be logical to assume that despite the country's advanced technological 
development, globalization trends that lead to social and cultural changes are slowly being introduced here. At the same time, some authors emphasize the uniqueness of Japan's culture and describe it as a "recipient country in the process of cultural exchange," capable of appropriating foreign developments and creating something authentic on their basis, and a people who voluntarily embrace foreign cultural influence (Belov, 2017).

In the recent academic literature, only a few publications are relevant to the study of the economic mind and behavior of modern Japanese people. The vast majority of these papers were written by economists (Dekle and Kletzer, 2003; Beckmann et al., 2008), and do not address the psychological context of the problem. The studies that compare the economic mind and behavior of modern residents of Russia and Japan are also very rare. In particular, the famous book "Sakura and Oak" by V. Ovchinnikov (Ovchinnikov, 2005), which has been translated into Japanese and has received awards both from the Japanese and Russian parties, is rather of a popular and journalistic than scientific nature. Among available scientific publications, it is worth paying attention to studies of the investment behavior of Japanese people (Yoshino, Taghizadeh-Hesary, 2016; Beckmann et al., 2008), entrepreneurial (Yu. B. Stonogin), and domestic behavior (Baranski et al., 2017), attitudes towards savings (Skidmore, 2001; Makin, 2002; Faruqee and Muhleisen, 2003; James and Suto, 2011) and banks (James, Suto, 2011), as well as studies of Japanese consumers (Nagayasu, 2017; Synodinos, 2001). In the context of this study, it is relevant to examine the paper that explores the attitudes of Japanese youth towards their work, future, and competencies (Uchida and Norasakkunkit, 2015), which revealed major changes in values and lifestyles of the new generation in Japan, manifested in the economic sphere as well.

The existing deficiency of studies in this direction emphasizes the relevance of this research and establishes its purpose to identify what characteristics of the psychological time predict the features of the economic mind of young people in Russia and Japan.

The following hypotheses were formulated on the basis of the previous studies:

H1: There are components of the psychological time of an individual, which are universal predictors of shaping economic attitudes in the conditions of globalization.

$\mathrm{H} 2$ : There are components of the psychological time of an individual, which are specific (culturally determined) predictors of shaping economic attitudes in the conditions of globalization.

\section{Methods and Sample}

The study was conducted on a sample of students from regional Russian and Japanese universities. The sample size comprised of 540 people: 293 Russian students aged 18-23 years (75 males and 218 females) and 247 Japanese students aged 18-24 years (121 males and 126 females).

To analyze the peculiarities of economic mind, the "Questionnaire of Economic Attitudes" (Deyneka and Zabelina, 2018) was used. This questionnaire comprehensively characterizes the field of economic attitudes of a personality; it included various spheres of the economic behavior of the owner (attitude to money, property, saving and investment behavior), the consumer, the entrepreneur, and the employee.

The theoretical basis of the study is the model of relation to time proposed by T. Nestik (2015). This model includes four components of the relation to time. The value and motivational component include the subjective importance of time as an irreplaceable resource. The cognitive component is illustrated by time perspective, temporal aspects of identity, etc. Affective component reflects emotional relation to time, and behavioral one describes preferred methods of time organization (Nestik, 2015, p.100). Inventory of Time Value as an Economic Resource by Usunier (Nestik, 2015) was used to explore the content of the value and motivational component of psychological time. To study the cognitive 
component of psychological time, the Zimbardo Time Perspective Inventory (Mitina and Sirtzova, 2008) was used. In order to identify the content of the affective component of psychological time, Attitudes towards Time (Nuttin, 2004) was used. This technique is based on a semantic differential, allowing us to study emotional attitude to the past, present, and future. Inventory of Polychronic Values (Nestik, 2015) was used to study the content of the behavioral component of psychological time.

Before the main study, the techniques were translated from Russian into Japanese (direct and reverse translation), and all necessary validation procedures were performed. The forms of the questionnaires were presented to the respondents in hand copy. The data were processed using SPSS 24.0. statistical package.

\section{Results and Discussion}

At the first stage of the study, the components of the psychological time of Japanese and Russian students were compared. The results of the comparative analysis revealed differences in each component of psychological time. The results of the comparison of the cognitive component of psychological time are shown in Table 1.

Table 1. Results of comparative analysis of a cognitive component of psychological time for Russians and Japanese.

\begin{tabular}{lcccc}
\hline & \multicolumn{2}{c}{ M } & U & p \\
\cline { 2 - 3 } & Russians & Japanese & & \\
\hline Past Negative & 2.87 & 3.21 & 34130 & 0.000 \\
\hline Present Hedonistic & 3.06 & 3.26 & 38878.5 & 0.000 \\
\hline Future & 3.24 & 3.33 & 45775.5 & 0.729 \\
\hline Past Positive & 3.46 & 3.23 & 38234.5 & 0.000 \\
\hline Present Fatalistic & 2.74 & 2.89 & 38256 & 0.000 \\
\hline
\end{tabular}

Japanese students are more concerned with the past, both positive and negative; they tend to be more attentive to their experiences. They also have an emotional response to joyful and sad events. At the same time, they are more focused on the present so that they can get positive emotions from current events and fully experience every moment of their existence. Furthermore, Japanese students are more inclined to believe that what happens to them in the present is predetermined and is not dependent on their efforts. At the same time, there are no differences in their future orientations. Regardless of their cultural background, students are concerned about their future, they make plans, and they seek to bring a sense of certainty in order to better understand what is about to happen in their professional and personal lives.

Analysis of differences in the emotional component of psychological time revealed that Japanese students are generally more self-restrained in positive emotions when evaluating their time than Russian students who are more optimistic (Table 2).

Table 2. Results of comparative analysis of an affective component of psychological time for Russians and Japanese.

\begin{tabular}{lccccc}
\hline & \multicolumn{2}{c}{ M } & U & $\mathrm{p}$ \\
\cline { 2 - 4 } & Russians & Japanese & & \\
\hline Attitude toward the past & 2.74 & 3.37 & 31408.5 & 0.000 \\
\hline Attitude toward the present & 2.78 & 3.11 & 38667 & 0.000 \\
\hline Attitude toward the future & 2.32 & 3.25 & 26026.5 & 0.000 \\
\hline
\end{tabular}


Japanese students have more neutral feelings of their past, present, and future. Time is more emotionally balanced (not causing either pleasant or unpleasant emotions). Time seems to be quite eventful, passing at an average pace (neither fast nor slow), moderately challenging, moderately successful, and moderately interesting. The Russian sample is more characterized by a sense of personal control over the past, present, and future. Russians perceive their time as more meaningful, active, and being their own. For the Japanese sample, on the contrary, such control is less expressed. In their minds, time is less significant, more passive, and refers primarily to a certain social space rather than a person. This is a reflection of the fatalistic perception of time in Japanese culture.

The behavioral component of psychological time also revealed significant differences. Russian students are more inclined to polychronism than Japanese is $(p=0.013)$. While Russian students are calm about doing several things at once, shifting their attention, the Japanese prefer to finish one task before taking up the other. The results conform the cultural differences identified by other authors (Lewis, 1996). Differences in the value and motivational component of the psychological time $(\mathrm{p}=0.001)$ were also found. Russian students have a more precise view of the value of time as an economic resource; they can easily transfer time into money and can calculate the value of their time. For Japanese students, time is not necessarily so tightly bound to money. For example, they are more comfortable with standing in line (a waste of time) because it is part of public rules. Then, the expression of economic attitudes in Japanese and Russian samples was compared (Table 3).

Table 3. Results of comparing the expression of economic attitudes of Japanese and Russian students.

\begin{tabular}{lcccc}
\hline Indicators & \multicolumn{2}{c}{$\mathrm{M}$} & $\mathrm{U}$ & $\mathrm{p}$ \\
\cline { 2 - 3 } & Russia & Japan & & \\
\hline Rational purchase decisions & 3.64 & 4.40 & 33041 & 0.000 \\
\hline Consumer satisfaction & 4.04 & 5.38 & 28493 & 0.000 \\
\hline Willingness to save money & 5.40 & 4.93 & 40935.5 & 0.001 \\
\hline $\begin{array}{l}\text { Confidence in the future because of } \\
\text { savings }\end{array}$ & 3.27 & 2.91 & 42193 & 0.005 \\
\hline Financial literacy & 3.97 & 2.60 & 25637.5 & 0.000 \\
\hline Consumer activity & 5.03 & 4.91 & 44691 & 0.084 \\
\hline Willingness to invest & 3.46 & 3.01 & 41908 & 0.003 \\
\hline $\begin{array}{l}\text { Activity and rationality in the sphere of } \\
\text { banking services }\end{array}$ & 5.09 & 4.50 & 38294 & 0.000 \\
\hline Distrust in banks & 3.61 & & & \\
\hline Cognitive economic activity & 3.76 & 2.97 & 37186 & 0.000 \\
\hline $\begin{array}{l}\text { Importance of independent economic } \\
\text { achievements }\end{array}$ & 6.21 & 5.35 & 32015 & 0.000 \\
\hline Economic ambitions & 5.48 & 3.66 & 21866.5 & 0.000 \\
\hline Negative attitude towards entrepreneurs & 3.21 & 2.72 & 40445 & 0.000 \\
\hline Real estate activities & 3.98 & 2.91 & 33767 & 0.000 \\
\hline Financial optimism & 5.12 & 3.87 & 28363.5 & 0.000 \\
\hline Priority of money over vocation & 4.10 & 3.62 & 40172.5 & 0.000 \\
\hline Importance of financial status & 4.99 & 3.88 & 31014.5 & 0.000 \\
\hline Awareness of consumer irrationality & 5.78 & 4.49 & 24563 & 0.000 \\
\hline Financial illiteracy & 4.33 & 5.48 & 29975 & 0.000 \\
\hline Social responsibility of wealth & 4.17 & 4.45 & 43606 & 0.026 \\
\hline Priority of money over health & 3.40 & 2.64 & 37139.5 & 0.000 \\
\hline & & & & \\
\hline & & & & \\
\hline
\end{tabular}

The results of the comparison revealed significant differences in most of the indicators. The Japanese are more rational in their consumer behavior $(p=0.000)$, more satisfied with 
their consumer opportunities $(p=0.000)$, but less willing to save money $(p=0.001)$ and therefore less sure about the future $(\mathrm{p}=0.005)$. This difference can be explained by a relatively more stable Japanese economy, a higher standard of life in which young people do not have to worry about their personal savings. In addition, statistics show that Japanese people start saving (usually in a pension fund) from the moment of getting a job and earning a steady income.

The differences in economic mind are strikingly evident in the parameters of financial optimism and economic aspirations. Russian students are much more confident that their income level will increase in the future $(\mathrm{p}=0.000)$; they would like to hold more financial resources than other people $(\mathrm{p}=0.000)$. In general, it can be noted that students in both countries have a low assessment of their financial literacy, despite the fact that they manage to get higher education and work at the same time in order to achieve financial freedom. The Japanese see themselves as even less knowledgeable in financial matters $(p=0.000)$ than Russian students. Another notable fact is the low willingness of young people in both countries to invest in high-risk projects, but Russian students still have higher willingness than Japanese $(\mathrm{p}=0.003)$. This fact can be explained by the lack of such experience and 'free' money among students, as well as their lack of knowledge in this area, as evidenced by opinions on financial literacy.

Students in both study groups have a rather low level of cognitive activity in economic matters: they have little interest in economic life in the country and in the world, while Japanese students are even less active than Russian students are $(\mathrm{p}=0.000)$. In Russia, students are more focused on the global economic experience than on the regional aspects of economic development, while Japanese students are more focused on the domestic aspects of economic development. Young people in Russia are also more active in the sphere of consumption (including banking sphere and real estate) than in Japan $(p=0.000)$, which can be explained not only by the peculiarities of national mentality but also by the influence of globalization. According to the results of the study, it is possible to draw a conclusion about the differences in the system of values between Russian and Japanese students. Thus, Russians need external conditions largely for successful implementation in Russian society. These include regional security, a good environmental situation, successful careers, material well-being, a stable family, peace in the world, and social support from the government (an external locus of control) (Vasilyeva and Yagnakova, 2019). Japanese students demonstrate a great dependence on internal factors (internal locus of control) in this aspect.

At the same time, Japanese students value their own vocation $(\mathrm{p}=0.000)$ and health $(p=0.000)$ over money higher as compared to Russians. The latter are more likely to choose high pay jobs at the expense of their own health and vocation. This can be understood as a connection to instability and tragic historical experiences (the Great Patriotic War, the collapse of the Soviet Union, Perestroika, and the modern financial crisis), as well as a stronger focus on Western values (materialism, rationality, individualism) in the consciousness of Russian students.

Another characteristic of Japanese students is that they have more confidence in financial institutions $(p=0.000)$ and actors $(p=0.000)$ than Russian students, and they share a greater belief in the responsibility of the rich towards the poor $(\mathrm{p}=0.026)$. This feature of the high social responsibility of entrepreneurs in Japanese society has been repeatedly discussed in academic literature (e.g., Karnyshev and Vinokurov, 2010).

At the next stage of our study, regression analysis was applied, the results of which suggest different determinations of economic mind in the compared countries. Particularly, the rational attitude to purchases (Russians $\mathrm{R}=0.228 ; \mathrm{R} 2=0.052 ; \mathrm{F}=5.293 ; \mathrm{p} \leq 0.001$, Japanese $\mathrm{R}=0.259 ; \mathrm{R} 2=0.067 ; \mathrm{F}=11.787 ; \mathrm{p} \leq 0.001)$ is contributed by the orientation of respondents to the future, but with different character. While Japanese students' attempts to 
think about the future $(\beta=0.204)$ strengthen rationality in consumer behavior (make them more serious and conscious in the present), Russian students, on the contrary, focus on thinking about future plans $(\beta=-0.224)$ increases irrationality of economic behavior. Perhaps, the uncertainty of the future contributes to the development of irresponsible behavior in the present among Russian students, when the connection between the present and the future is lost in their consumer behavior in everyday life. This alarming symptom shows that a consumer society is dangerous for a young person's personality.

Moreover, rationality in consumer behavior is determined by the positive attitude of young Japanese towards the past $(\beta=-0.154)$. In fact, past, present, and future are combined in the economic mind of Japanese students and shape a careful, conscious attitude towards what they buy. In addition to the negative contribution of the time perspective of the future, Russian students also have fatalistic $(\beta=0.142)$ and positive attitude to the present $(\beta=-$ 0.115 ) in shaping rational consumer behavior. Thus, the students in their consumer attitudes are focused only on the present, which may lead to consumption that does not take into account previous experience and does not develop responsibility for the consequences in the future (for example, overconsumption).

Cultural differences were also revealed in the determination of such an attribute as confidence in the future because of savings (Russian $\mathrm{R}=0.165 ; \mathrm{R} 2=0.027 ; \mathrm{F}=8.218 ; \mathrm{p} \leq 0.01$, Japanese $\mathrm{R}=0.346 ; \mathrm{R} 2=0.120 ; \mathrm{F}=22.196 ; \mathrm{p} \leq 0.001)$. While for Japanese students, it is due to a positive attitude to the past $(\beta=-0.326)$ and fatalistic attitude to the present $(\beta=0.125)$, for Russians, it is due to orientation to the future $(\beta=0.165)$. This fact reflects such features of Japanese mind as an orientation to the present and belief that everything is predetermined (Parieva, 2017). It is this belief that determines the confidence in the future for Japanese, while for Russian students, it is nourished by reflections on their future plans and the desire to implement them. The manifestation of these differences can be seen in the guidance system in the studied countries. The prototype of the vocational guidance approach in Russia is E.A. Klimov's three-factor model of "I want - I can - I need" (the study of personal preferences, consideration of psychophysiological possibilities, orientation to the needs of the labor market), and in Japan - S. Fukuyama's F-test (self-analysis, analysis of professions, professional tests). At present, the emphasis in Russia is placed on the promotion of career values, while in Japan, the emphasis is placed on the value of work as such, and the development of individual potential.

Similar differences were revealed in the determination of financial literacy (Russians $\mathrm{R}=0.221 ; \mathrm{R} 2=0.049 ; \mathrm{F}=7.484 ; \mathrm{p} \leq 0.001$, Japanese $\mathrm{R}=0.228 ; \mathrm{R} 2=0.052 ; \mathrm{F}=8.999 ; \mathrm{p} \leq 0.001$ ). For Russian students who want to be more knowledgeable in financial matters, it is more typical to rely on themselves, their strength in achieving goals $(\beta=0.298)$. They are ready to deny the pleasures of the present for the sake of achievements in the future $(\beta=-0.237)$. Japanese young people perceive financial literacy as something given to man by nature; they do not want to consciously improve it for the sake of future goals $(\beta=0.128)$ (remember that students of humanitarian directions were studied). They are grateful to their experience, which allows them to increase their knowledge in the field of finance (positive attitude to the past $\beta=0.193$ ). The manifestation of this pattern can be seen in the Russian trend of significant rejuvenation of top managers and implementation of state professional leadership programs (national projects, the program "Leaders of Russia," the Presidential Grant Foundation, etc.), thanks to which a positive attitude to "social elevators" is shaped in the minds of Russian youth. Japanese students, due to the sustainable concept of long-term employment, have a lower demand for active professional ambitions due to the difficulty of finding a key position at a young age, which is confirmed by a well-known Japanese proverb: "The nail that sticks out gets hammered down."

The activity which students show at a choice of the most favorable conditions of bank deposits (Russian $\mathrm{R}=0.199 ; \mathrm{R} 2=0.040 ; \mathrm{F}=12.010 ; \mathrm{p} \leq 0.01$, Japanese $\mathrm{R}=0.308 ; \mathrm{R} 2=0.095$; 
$\mathrm{F}=11.415 ; \mathrm{p} \leq 0.001$ ), is explained for the Russian sample by the positive attitude to the future (perception of it as bright, free, controlled, etc.) $(\beta=-0.199)$, and for the Japanese sample - the totality of understanding the value of time as an economic resource (importance of enrichment over time) $(\beta=0.202)$, as well as orientation towards the past, both positive $(\beta=0.208)$ and negative $(\beta=0.133)$. It can be concluded that the Japanese are more responsible and rational in choosing a bank, taking into account their experience, than the Russians, who are more emotional in this matter.

Negative attitudes towards entrepreneurs (Russians $\mathrm{R}=0.273 ; \mathrm{R} 2=0.075 ; \mathrm{F}=11.732$; $\mathrm{p} \leq 0.01$, Japanese $\mathrm{R}=0.312 ; \mathrm{R} 2=0.098 ; \mathrm{F}=9.775 ; \mathrm{p} \leq 0.001)$ are based on fatalistic attitude towards the events of the present (Japanese $\beta=0.188$, Russians $\beta=0.209$ ). On the contrary, sympathy for entrepreneurs is supported by the internal locus of control, faith in their own capabilities to manage the situation. This fact, which has been demonstrated more than once in studies of entrepreneurs, testifies to a similar image of a businessperson among students from different countries. However, in addition to the fatalistic present, this attitude is determined by the negative attitude of Russian students towards the present $(\beta=0.158)$ and the negative attitude towards the future $(\beta=0.144)$, as well as the low orientation towards the future $(\beta=-0.130)$ among the Japanese. It can be concluded that the Japanese see entrepreneurship as a possible future activity, unlike the Russians who associate it with the present.

Universal predictors of the economic mind of young people in both countries have been identified. For example, such a predictor is the value of time as an economic resource that contributes to the formation of consumer satisfaction attitudes (Japanese $\beta=0.130$, Russians $\beta=0.120$ ), cognitive economic activity (Japanese $\beta=0.127$, Russians $\beta=0.182$ ) and aspirations for saving money (Japanese $\beta=0.141$, Russians $\beta=0.176$ ). The association of time with money reflects the perception of time as linear and rational that corresponds to the Western tradition of psychological time. The influence of this attitude to time on the economic mind of young people in Japan and Russia may be a consequence of globalization processes in the world.

Another universal predictor of real estate activity in both samples is polychronicity - the tendency to do several things at once (Japanese $\beta=0.155$, Russians $\beta=0.118$ ). This result can be explained by the fact that the purchase of a real estate for students is not the main task at the moment of their lives, it is of interest only to the most active, "polychronic" students. It is reasonable that financial optimism of students (the belief that their income level will increase in the future) can be explained by a positive attitude to the future (Japanese $\beta=-$ 0.356 , Russians $\beta=-0.251$ ) and attitude to time as an economic resource (Japanese $\beta=0.120$, Russians $\beta=0.215)$. In addition, for the Russian sample, such characteristics of psychological time as an orientation to a positive past $(\beta=0.216)$ and self-confidence to change the situation today contribute to financial optimism (fatalistic present $\beta=-0.161$ ). That is, for Russians, financial optimism is more complexly determined from the point of view of psychological time - a set of past, present, and future.

\section{Conclusion}

The study results confirm both hypotheses. Universal time predictors of economic attitudes can be considered to be the attitude towards time as an economic resource, polychronicity/monochronicity, and a positive image of the future. Culturally determined characteristics of psychological time that predict the formation of economic attitudes, are orientation to the past and present (including fatalistic) for the Japanese and orientation to the future for the Russians.

The study revealed a more systematic temporal determination of Japanese economic mind, which includes not only oriented towards the future but also taking into account past 
experience as well as self-perception in the present. Russian youth is more future-oriented in developing economic attitudes. In the development of some economic attitudes (the value of independent economic achievements, activity in the banking sphere, etc.), a greater contribution for representatives of Russian students make an affective component of the psychological time of personality, and for Japanese students - cognitive. This may indicate that students in Russia take economic life less seriously than Japanese students. An important role in both countries is played by the perception of time as an economic resource, measuring it in money, which is characteristic of the era of economic globalization.

According to the obtained results, the psychological time of an individual being included in the process of globalization as a predictor of economic consciousness directly corresponds with the cultural and value picture of the world. Values and ideals as social and cultural needs of a person, are thought images of what one does not have, but wants to achieve, so they are the project of the future. Consequently, economic attitudes, as part of the economic culture of countries, carry the time vector of an individual.

The reported study was funded by RFBR according to the research project № 18-013-00201 A

\section{References}

1. Antonides, G. and Van Der Sar, N.L. (1990), "Individual expectations, risk perception and preferences in relation to investment decision making", Journal of Economic Psychology, Vol. 11 No. 2, pp. 227-245

2. Armitage, C.J. and Conner, M. (2000), "Attitudinal ambivalence: a test of three key hypotheses", Personality and Social Psychology Bulletin, Vol. 26, pp. 1421-1432.

3. Baranski, E.N. et al. (2017) Comparisons of Daily Behavior Across 21 Countries. Social psychological and personality science, 8 (3), 252-266

4. Beckmann, D., Menkhoff, L., Suto, M. (2008). Does culture influence asset managers' views and behavior? Journal of economic behavior \& organization, 67 (3-4), 624-643

5. Chaiken, S. and Yates, S. (1985), “Affective-cognitive consistency and thoughtinduced attitude polarization", Journal of Personality and Social Psychology, Vol. 49, p. 1470-1481.

6. Conner, M. and Sparks, P. (2002), “Ambivalence and attitudes", European Review of Social Psychology, Ed. by W. Stroebe, M. Hewstone, Vol. 12, pp. 37-70.

7. Dekle, R., Kletzer, K. (2003). The Japanese banking crisis and economic growth: Theoretical and empirical implications of deposit guarantees and weak financial regulation. Journal of the japanese and international economies, 17 (3), 305-335

8. Deyneka O.S. Economic mind: phenomenology, structure and potential development // Culture and economic behavior: a collection of articles (in Russian) / Under general ed. By N.M. Lebedeva, A.N. Tatarko. Moscow:. Maks Press. 2011. pp. 118-148.

9. Dinauer L.D. and Fink, E.E. (2005), "Interattitude structure and attitude dynamics", Human Communication Research, Vol. 31, pp. 1-32.

10. Graham R.J. The role of perception of time in consumer research // Journal of Consumer Research. 1981. N 7. P. 335-342. 469.

11. Faruqee, H., Muhleisen, M. (2003) Population aging in Japan: demographic shock and fiscal sustainability. Japan and the world economy, 15 (2), 185-210 
12. Furnham, A. (1996), "Attitudinal correlates and demographic predictors of monetary beliefs and behaviors", Journal of Organizational Behavior, Vol. 17 No. 4, pp. 375388.

13. Furnham, A. (1982), "The Protestant work ethic and attitudes towards unemployment". Journal of Occupational Psychology, Vol. 55 No. 4, pp. 277-285.

14. Furnham, A. (1985), "Why Do People Save? Attitudes to, and Habits of Saving Money in Britain”, Journal of Applied Social Psychology, Vol. 15 No. 5, pp. 354-373

15. Horikawa Atsushi. Society and market: comparative analysis of Japan and Russia // Thesis for the degree of Candidate of Sociological Sciences. - Saint Petersburg, 2007. - 152 p. URL: https://www.dissercat.com/content/obshchestvo-i-rynok-sravnitelnyianaliz-yaponii-i-rossii (access date: 20.04.2020).

16. Hudyakova N.L. Axiological basics of human behavior: training manual / N. L. Hudyakova. Chelyabinsk: Editorial of Chelyabinsk State University, 2010. - 109 p.

17. Huskinson, T.L.H. and Haddock, G. (2006), "Individual differences in attitude structure and the accessibility of the affective and cognitive components of attitude", Social Cognition, Vol. 24, pp. 453-468.

18. James, J.A., Suto, I. (2011) Early twentieth-century Japanese worker saving: precautionary behaviour before a social safety net. Cliometrica, 5 (1), 1-25

19. Kalil, A., Schweingruber, H.A. and Seefeldt, K.S. (2001), "Correlates of employment among welfare recipients: Do psychological characteristics and attitudes matter?" American Journal of Community Psychology, Vol. 29 No. 5, pp. 701-723.

20. Karnyshev A.D., Vinokurov M.A. Ethnocultural traditions and innovations in economic psychology. Moscow.: Editorial of Institute of Psychology of the Russian Academy of Sciences, 2010

21. Krech, D. and Crutchfield, R. (1948), Theory and Problems of Social Psychology, New York: McGraw-Hill.

22. Lea, S.E.G., Webley, P. and Levine, R.M. (1993), "The economic psychology of consumer debt”. Journal of Economic Psychology, Vol. 14 No. 1, pp. 85-119.

23. Lea, S.E.G., Webley, P., Walker, C.M. (1995) "Psychological factors in consumer debt: Money management, economic socialization, and credit use", Journal of Economic Psychology, Vol. 16 No. 4, pp. 681-701.

24. Levine R. A Geography of time: The Temporal Misadventures of a Social Psychologist, or How Every Culture Keeps Time Just a Little Bit Differently. N.Y.: Basic Books, 1997.

25. Lewis R.D. When Cultures Collide Managing successfully across cultures. London: Nicholas Brealey P., 1996.

26. Lewis, A. and Furnham, A. (1986), "Reducing unemployment: Lay beliefs about how to reduce current unemployment", Journal of Economic Psychology, Vol. 7 No. 1, pp. 75-85.

27. Makin, A.J. (2002) Saving, productivity and national income: a discrete-time geometric framework. Japan and the world economy, 14 (2), 233-241

28. Mewse, A.J., Lea, S.E.G. and Wrapson, W. (2010), "First steps out of debt. Attitudes and social identity as predictors of contact by debtors with creditors", Journal of Economic Psychology, Vol. 31 (6), pp. 1021-1034

29. Nagayasu, J. (2017) Inflation and consumption of nontradable goods: Global implications from regional analyses. International review of economics \& finance, 48 , 478-491 
30. Nestik T.A. (2015). Social'no-psihologicheskaya determinaciya gruppovogo otnosheniya $\mathrm{k}$ vremeni [Social and psychological determination of group attitude to time] Doctoral thesis. Moscow

31. Nuttin, Zh. (2004). Motivaciya, dejstvie i perspektiva budushchego [Motivation, action and future perspective]. Moscow: Smysl.

32. Ovchinnikov V.V. Sakura and Oak. Moscow: Editorial AST, 2017. 605 p.

33. Pariyeva N.E. (2017). Koncept «vremya» v yaponskoj lingvokul'ture [Concept "time" in Japanese linguoculture]. Doctoral thesis. Moscow

34. Rokeach, M. (1986), "The Nature of Attitudes", International Encyclopedia of the Social Sciences, D. L. Sills. Crowell.

35. Rosenberg, M.J. (1960), “A Structural Theory of Attitude Dynamics”, Public Opinion Quarterly, Vol. 24, pp. 319-340.

36. Sircova, A. (2008). Vozrastnaya dinamika vremennoi perspektivy lichnosti [Age dynamics of time perspective of the personality]. Moscow.

37. Skidmore, M. (2001) Risk, natural disasters, and household savings in a life cycle model. Japan and the world economy, 13 (1)., 15-34.

38. Smith M.B. (1986), "Attitude Change", International Encyclopedia of the Social Sciences, D. L. Sills. Crowell.

39. Stonogina Yu.B. Time and space in Japanese business. Bulletin of Moscow State Institute of International Relations, 2012, No. 3(24), pp. 148-152.

40. Synodinos, N.E. (2001) Understanding Japanese consumers: Some important underlying factors. Japanese psychological research, 43 (4), 235-248

41. Trompenaars, F., \& Hampden-Turner, Ch., (1997). Riding the Waves of Culture, Nicholas Brealey Publ. Ltd.

42. Uchida, Y., Norasakkunkit, V. (2015) The NEET and Hikikomori spectrum: Assessing the risks and consequences of becoming culturally marginalized. Frontiers in psychology, 6, 1117

43. Vale, G.L., Flynn, E.G. \& Kendal, R.L. (2012). Cumulative culture and future thinking: Is mental time travel a prerequisite to cumulative cultural evolution? Learning and Motivation, 43: 220-230.

44. Vasilyeva S.A., Yagnakova E.Z. Spiritual value of Russian youth in the context of the implementation of National Policy Strategy // Proceedings of All-Russian (with International Participation) "VIII RASULEVSKIE READINGS: ISLAM IN THE HISTORY OF MODERN RUSSIAN LIFE" - Chelyabinsk: Editorial of Chelyabinsk State University, 2019. - p p. 182-186 (in Russian). URL: https://www.elibrary.ru/item.asp?id=41215699 (access date: 20.04 .2020$)$.

45. Von Stumm, S., Fenton O'Creevy, M. and Furnham, A. (2013), "Financial capability, money attitudes and socioeconomic status: Risks for experiencing adverse financial events", Personality and Individual Differences, Vol. 54 No. 3, pp. 344-349.

46. Yoshino, N.; Taghizadeh-Hesary, F. (2016) Monetary Policy in the Japanese Economy Incorporating Energy Prices. Monetary policy and the oil marketю ADB Institute Series on Development Economics, 93-106

47. Zabelina E., Deyneka O. and Tsiring D. (2019). Entrepreneurial attitudes in the structure of students' economic minds. International Journal of Entrepreneurial Behavior \& Research, Vol. 25 No. 8, pp. 1621-1633. https://doi.org/10.1108/IJEBR04-2018-0224. 